\title{
Quality of life and mastication in denture wearers and cleft lip and palate adults
}

\author{
Marina Rechden Lobato PALMEIRO(a) \\ Mariana Bauer BRONSTRUP(a) \\ Justin DURHAM(b) \\ Angus WALLS(c) \\ Rosemary Sadami Arai SHINKAI (a)
}

(a) Pontifícia Universidade Católica do Rio Grande do Sul - PUC-RS, Dental School, Porto Alegre, RS, Brazil

(b) Newcastle University, School of Dental Sciences, United Kingdom

(c)Edinburgh Dental Institute, Edinburgh, United Kingdom

Declaration of Interest: The authors certify that they have no commercial or associative interest that represents a conflict of interest in connection with the manuscript.

\section{Corresponding Author:}

Marina Rechden Lobato Palmeiro

E-mail:marina.lobato@pucrs.br

Submitted: November 04. 2017

Accepted for publication: August 17, 2018

Last revision: September 12, 2018
Abstract: The impact of oral rehabilitation on masticatory function and oral health-related quality of life (OHRQoL) may vary with the experience of the individual with tissue loss. Our hypothesis is that patient-centered outcomes vary among adults who have experienced large defects in the maxilla due to congenital or acquired conditions even after oral rehabilitation to restore aesthetics and function. This study compared OHRQoL, perceived masticatory ability, maximum bite force (MBF), and symptoms of pain and depression among subjects with acquired (edentulous maxilla) and congenital (cleft lip and palate) loss of oral tissues in the maxilla after dental treatment. A gender-matched sample $(n=60)$ of cleft lip and palate $(C L P)$, maxillary denture wearers (DENT) and controls (CONT) was recruited. OHRQoL was assessed using OHIP-14. Chewing was evaluated through a masticatory ability questionnaire and by MBF. The RDC/TMD Axis II questionnaire was used to assess symptoms of pain and depression. Data were analyzed by Fisher's test, Kruskal Wallis test, and Spearman correlation coefficients. CLP showed higher OHIP-14 and depression scores than DENT and CONT ( $p$ < 0.05). Sub-analysis by OHIP-14 items (\%FOVO) showed higher prevalence of psychological impact for CLP and of functional impacts for DENT. The number of foods difficult to chew, of food textures difficult to chew, and avoided foods were similar between CLP and DENT. OHIP$14, \mathrm{MBF}$, and depression scores showed significant correlation $(\mathrm{p}<0.05)$. The results suggest that adults with treated CLP or maxillary DENT have chewing impairment and lower MBF than healthy subjects, with different psychological and functional impacts.

Keywords: Oral Health; Quality of Life; Surveys and Questionnaires; Dental Prosthesis; Dental Implants.

\section{Introduction}

Oral health status may impact routine daily activities, such as chewing and tasting food, speaking and psychosocial functioning., ${ }^{1,2,3}$ According to the Global Burden of Disease 2015 study, ${ }^{4}$ total tooth loss was the leading cause of disability-adjusted life year (DALY) estimates of oral conditions for the period of 1990 to 2015. Loss or derangement of maxillary hard and soft tissues occurs in subjects with both cleft lip and palate (CLP) and maxillary complete dentures. However, the life history and experiences with oral tissue loss may affect differently the functional outcomes of the oral rehabilitation. 
Clefts of the lip and/or palate are innate nonsyndromic orofacial defects, which include a range of disorders affecting the face and oral cavity. Alterations in appearance, speech, hearing, and feeding can lead to long-lasting adverse outcomes that require a multidisciplinary approach to improve function, esthetics, satisfaction, social integration, and overall well-being. $3.5,6,7,8,9$ Similarly to CLP subjects, maxillary edentulous patients have large loss of teeth and oral tissues in the maxilla and may present compromised function and diminished self-esteem, which can be improved with oral rehabilitation with complete dentures. ${ }^{2,10,11,12}$ Nevertheless, maxillary edentulous subjects often experience major oral health problems at a later stage in life leading to more dental loss due to different etiologies. It is still unclear if specialized dental treatment in both groups effectively restores function, satisfaction and overall quality of life to the levels reported by normal subjects.

We hypothesized that patient-centered outcomes would vary between edentulous and CLP adults, which are subjects with large defects in the maxilla due to congenital or acquired conditions, even after oral rehabilitation to restore aesthetics and function. The specific aims of this study were to compare quality of life, symptoms of pain and depression, perceived masticatory ability and maximum bite force among three groups of adult subjects: patients with repaired CLP, maxillary denture wearers, and healthy dentate subjects.

\section{Methodology}

The study design was observational, crosssectional, and correlational, and followed the STROBE guidelines. The research protocol was approved by the Institutional Ethics Committee of the Pontifical Catholic University of Rio Grande do Sul (PUCRS) in compliance with the national ethical regulations and the Declaration of Helsinki.

A non-probabilistic sample of 60 consecutive subjects was recruited at the PUCRS. Inclusion criteria were adult subjects with the cognitive ability to understand the study and its questionnaires and that signed the written informed consent, good oral and general health, absent of disease or any pathological process, and presence of occlusal support at the first molar. The patients who were edentulous in the maxilla had to have at least 6-months experience of maxillary denture wear. The selected subjects were divided into three gender-matched groups:

1. CLP: Patients treated since childhood at the PUCRS by a multidisciplinary team of professionals from dentistry, psychology and medicine, and at the specialty course in Prosthodontics. Patients had completed surgical repair, orthodontics, and oral rehabilitation for CLP with partial fixed prostheses supported by either natural teeth or dental implants in both arches $(n=20$, mean $[ \pm$ SD $]$ age $=30.6 \pm 10.55$ years);

2. DENT: Maxillary denture wearers with natural dentition or fixed prostheses supported by either natural teeth or dental implants in the lower arch $(n=20$; mean $[ \pm S D]$ age $=62.9 \pm 9.46$ years); and

3. CONT: Healthy fully dentate subjects $(\mathrm{n}=20$, mean $[ \pm S D]$ age $=23.2 \pm 0.63$ years).

All subjects signed an informed consent form before the procedures. Data were collected by a single trained investigator during a face-to-face structured interview and clinical examination. Three selfcompletion questionnaires were used to assess oral health related quality of life (OHRQoL): 1) OHIP 14, ${ }^{13}$ 2) masticatory ability, ${ }^{14}$ and 3) symptoms of orofacial pain and depression (RDC/TMD Axis II). ${ }^{15}$

\section{Maximum bite force}

Maximum bite force (in Newtons) was measured using a cross-arch force transducer (Sensotec 13/244502 , Columbus, $\mathrm{OH}$ ) placed in the molar region. After instructions about the procedure, all subjects were asked to bite at their maximum comfortable force, and the mean of three recordings was used as the maximum bite force. ${ }^{16}$

\section{Quality of life}

The subjects were asked how frequently they experienced the impact of each item in the preceding 12 months. The OHIP-14 summary score was calculated using the OHIP Additive (OHIP-ADD) method. ${ }^{17}$ In addition a 'fairly often' or 'very often' (FOVO) analysis was undertaken for each item. The difference in item 
prevalence between the test groups and the control group was calculated, and items were ranked in a descending order by their differences. . $^{5,7,18}$

\section{Masticatory ability questionnaire ${ }^{14}$}

Questions of perceived masticatory ability included three domains: 1) Types of foods difficult to chew; 2) Food textures difficult to chew; 3 ) Avoided foods. Responses were categorized in ' $0=$ no problem to chew' and ' 1 = if there is any difficulty to chew'. Self-reported average meal duration was recorded in minutes.

\section{Pain and depression}

The RDC questionnaire was analyzed using the scoring system described in the RDC/TMD Guidelines..$^{15}$ Chronic Pain Grade Classification (GCP) scores were defined as follows: $0=$ no TMD pain in the previous 6 months; low disability grade $\mathrm{I}=$ low intensity (characteristic pain intensity $<50$, and less than 3 disability points); grade $\mathrm{II}=$ high intensity (characteristic pain intensity $>50$, and less than 3 disability points); high disability grade III= moderately limiting ( 3 to 4 disability points, regardless of characteristic pain intensity); grade IV $=$ severely limiting 5 to 6 disability points regardless of characteristic pain intensity. Depression scores less than 0.5 were considered as 'normal'. ${ }^{19}$

\section{Statistical analysis}

Data were analyzed with Statistical Package for the Social Sciences PC version 19.0 (SPSS Inc., Chicago, USA) using Fisher's exact test for categorical data (self-reported bruxism and chewing ability), and Kruskal Wallis test to compare OHIP-14 scores, RDC scores, maximum bite force and perceived masticatory ability data.

\section{Results}

Table 1 shows the clinical characteristics of the sample. CLP and DENT subjects had lower maximum bite force than controls $(p<0.001)$. CLP subjects reported greater impact in terms of OHQoL $(p<$ 0.001 ) and more symptoms of depression than the other two groups. There was no difference between DENT and CONT for the OHIP or the RDC outcomes.

Table 1. Clinical characteristics of the sample $(n=60)$.

\begin{tabular}{|c|c|c|c|c|}
\hline \multirow{2}{*}{ Variable } & CLP & DENT & CONT & \multirow{2}{*}{$p$-value } \\
\hline & $(n=20)$ & $(n=20)$ & $(n=20)$ & \\
\hline \multicolumn{5}{|l|}{ Bite force $(N)$} \\
\hline Mean (SD) & $337(204)^{a}$ & $263(113)^{a}$ & $838(287)^{b}$ & $<0.001^{*}$ \\
\hline Self-reported Bruxism*** & & & & $0.641^{* *}$ \\
\hline Possible Bruxism & 3 & 5 & 6 & \\
\hline No & 17 & 15 & 14 & \\
\hline \multicolumn{5}{|l|}{ OHIP-1 4 ADD**** } \\
\hline Median $\left(25^{\text {th }}-75^{\text {th }}\right)$ & $12.00(7.50-23.00)^{a}$ & $1.50(0.00-10.00)^{b}$ & $2.00(0.00-3.00)^{b}$ & $<0.001^{\dagger}$ \\
\hline \multicolumn{5}{|l|}{ RDC/TMD Axis II+**** } \\
\hline \multicolumn{5}{|l|}{ Chronic pain grade } \\
\hline Grade 0 & 14 & 17 & 13 & \\
\hline Grade I & 5 & 3 & 5 & \\
\hline Grade ॥ & 0 & 0 & 2 & \\
\hline Grade III & 1 & 0 & 0 & \\
\hline Grade IV & 0 & 0 & 0 & \\
\hline \multicolumn{5}{|l|}{ Depression } \\
\hline Median (25th-75th) & $0.42(0.15-0.77)^{\circ}$ & $0.00(0.00-0.60)^{b}$ & $0.05(0.00-0.30)^{b}$ & $0.007^{*}$ \\
\hline
\end{tabular}


There was no significant difference among the groups for chronic pain scores from the RDC questionnaire with generally low levels of pain and/or disability.

The overall OHIP-14 score for CLP was two-fold higher (worse oral health-related quality of life) than in DENT and CONT with nominal differences of median scores in some OHIP-14 domains between groups (Table 2). There was no difference between DENT and CONT in OHIP-14. Sub-analysis by OHIP-14 items (\% FOVO) showed higher prevalence of psychological items for CLP and of functional items for DENT (Table 3).
Table 4 shows the results of perceived masticatory ability of selected foods. The maximum number of foods difficult to chew, food textures difficult to chew, and avoided foods were similar between CLP and DENT and higher than CONT. CLP reported chewing difficulties mainly with raw, hard, sticky and gooey textures, and avoiding corn on the cob, apple skin and gum. Gum, caramel candies, and nuts, corresponding to sticky and hard textures, were reported as foods difficult to chew by DENT and particularly avoided $(\mathrm{p}<0.05)$.

Table 2. Median scores in each OHIP-14 domain among groups.

\begin{tabular}{|c|c|c|c|c|}
\hline \multirow{2}{*}{ Domain* } & \multirow{2}{*}{ OHIP Questions } & \multicolumn{3}{|c|}{ Median OHIP- 14 domain scores $(25 \mathrm{th}-75 \mathrm{th})(\mathrm{n}=20)$} \\
\hline & & CLP & DENT & CONT \\
\hline \multirow{2}{*}{ Functional limitation } & Q1. Trouble pronouncing words & \multirow{2}{*}{$2.0(0.5-3.5)$} & \multirow{2}{*}{$0.5(0-2.0)$} & \multirow{2}{*}{$0(0-0)$} \\
\hline & Q2. Felt sense of taste worsened & & & \\
\hline \multirow{2}{*}{ Physical pain } & Q3. Had painful aching in mouth & \multirow{2}{*}{$1.0(0-3.0)$} & \multirow{2}{*}{$0.5(0-2.0)$} & \multirow{2}{*}{$0(0-1)$} \\
\hline & Q4. Uncomfortable to eat foods & & & \\
\hline \multirow{2}{*}{ Psychological discomfort } & Q5. Been self-conscious & \multirow{2}{*}{$3.5(2-7.5)$} & \multirow{2}{*}{$0(0-4.0)$} & \multirow{2}{*}{$1.0(0-2.0)$} \\
\hline & Q6. Felt tense & & & \\
\hline \multirow{2}{*}{ Physical disability } & Q7. Diet been unsatisfactory & \multirow{2}{*}{$0(0-2.5)$} & \multirow{2}{*}{$0(0-1.0)$} & \multirow{2}{*}{$0(0-0)$} \\
\hline & Q8. Had to interrupt meals & & & \\
\hline \multirow{2}{*}{ Psychological disability } & Q9. Difficult to relax & \multirow{2}{*}{$2.0(0.5-4.0)$} & \multirow{2}{*}{$0(0-2.5)$} & \multirow{2}{*}{$0(0-0)$} \\
\hline & Q10. Been a bit embarrassed & & & \\
\hline \multirow{2}{*}{ Social Disability } & Q1 1. Irritable with other people & \multirow{2}{*}{$0(0-2.0)$} & \multirow{2}{*}{$0(0-0)$} & \multirow{2}{*}{$0(0-0)$} \\
\hline & Q12. Difficulty doing usual jobs & & & \\
\hline \multirow{2}{*}{ Handicap } & Q13. Felt life less satisfying & \multirow{2}{*}{$0(0-0)$} & \multirow{2}{*}{$0(0-0.5)$} & \multirow{2}{*}{$0(0-0)$} \\
\hline & Q14. Totally unable to function & & & \\
\hline
\end{tabular}

*The statements and their groupings are derived from the Oral Health Impact profile (OHIP-14).

Table 3. Ranking of OHIP- 14 items in a descending order by score in prevalence between CLP, DENT and CONT.

\begin{tabular}{|c|c|c|c|c|c|c|c|}
\hline \multirow{2}{*}{ OHIP No } & \multicolumn{3}{|c|}{ CLP FOVO compared with CONT } & \multirow{2}{*}{ Trend } & \multicolumn{3}{|c|}{ DENT FOVO compared with CONT } \\
\hline & Rank & $\%$ Dif & Subject & & Subject & Rank & $\%$ Dif \\
\hline Q10 & 1 & 45 & Embarrassment & & Embarrassment & 1 & 20 \\
\hline Q 05 & 2 & 35 & Self-conscious** & & Diet unsatisfactory & 1 & 20 \\
\hline Q 06 & & 30 & Felt tense & & Felt tense & 1 & 20 \\
\hline Q 01 & & 25 & Pronunciation & & Pain & 2 & 15 \\
\hline Q 02 & 5 , & 20 & Taste & & Taste & 2 & 15 \\
\hline Q 04 & .6 & 15 & Discomfort eating & & Discomfort eating & 2 & 15 \\
\hline Q 08 & $\gamma$ & 15 & Interrupt meals & & Pronunciation & 3 & 10 \\
\hline Q 11 & 0 & -15 & Irritable & & Self-conscious"* & 3 & 10 \\
\hline Q 07 & 7 & -10 & Diet unsatisfactory & & Life less satisfying & 3 & 10 \\
\hline Q 09 & 7 & 10 & Difficult to relax & & Interrupt meals & 4 & 5 \\
\hline Q 13 & 8 & 5 & Life less satisfying & & Difficult to relax & 4 & 5 \\
\hline Q 03 & 9 & 0 & Pain & & Irritable & 4 & 5 \\
\hline Q 12 & 9 & 0 & Difficulty with jobs & & Difficulty with jobs & 5 & 0 \\
\hline Q 14 & 9 & 0 & Unable to function & & Unable to function & 5 & 0 \\
\hline
\end{tabular}


Table 4. Masticatory characteristics of the sample $(n=60)$.

\begin{tabular}{|c|c|c|c|c|}
\hline \multirow{2}{*}{ Variable } & CLP & DENT & CONT & \multirow{2}{*}{$\mathrm{p}$-value } \\
\hline & $(n=20)$ & $(n=20)$ & $(n=20)$ & \\
\hline \multicolumn{5}{|l|}{ Number of foods difficult to chew } \\
\hline Maximum (out of 10 items) & 9 & 9 & 1 & \\
\hline Median (25th-75th) & $0(0-3.0)$ & $2.5(0-3.5)$ & $0(0-0)$ & $<0.001^{*}$ \\
\hline \multicolumn{5}{|c|}{ Number of food textures difficult to chew } \\
\hline Maximum (out of 6 items) & 5 & 6 & 1 & \\
\hline Median (25th 75th) & $1.0(0-3.0)$ & $1.0(0-2.0)$ & $0(0-0)$ & $0.001^{*}$ \\
\hline \multicolumn{5}{|l|}{ Number of avoided foods } \\
\hline Maximum (out of 10 items) & 10 & 10 & 2 & \\
\hline Median (25th-75th) & $2.0(.5-4.5)$ & $2.50(1.5-3.5)$ & $0(0-0)$ & $<0.001^{*}$ \\
\hline \multicolumn{5}{|l|}{ Self-reported chewing ability } \\
\hline \multicolumn{5}{|l|}{ Can you chew well? (count) } \\
\hline Yes & 11 & 14 & 20 & $0.002^{* *}$ \\
\hline No & 8 & 6 & 0 & \\
\hline Do not know & 1 & 0 & 0 & \\
\hline \multicolumn{5}{|l|}{ Self-reported meal duration (min) } \\
\hline Mean (SD) & $23(15)$ & $22(10)$ & $20(5)$ & $0.926^{*}$ \\
\hline
\end{tabular}

\section{Discussion}

To the best of the authors' knowledge, this is the first study to compare masticatory function and perceptions of OHRQoL in treated adult subjects with congenital or acquired major loss of maxillary function alone. The literature has shown the individual relationship between some study variables, but no study specifically assessed bruxism in CLP. The present findings showed that both treated adult CLP and DENT groups still had perceived chewing problems and diet restrictions, but their OHRQoL was influenced by different domains, which refutes the study null hypothesis. The clinician's awareness and understanding of these differences may lead to better results for the effective treatment of CLP and denture patients.

CLP subjects reported poorer quality of life and showed more symptoms of depression than DENT and CONT; however, the mean depression score in this group was within the range established by Dworkin et al. ${ }^{19}$ as normal. The three types of cleft (preincisive foramen clefts, transincisive foramen clefts, and incisive foramen clefts) were combined in a single CLP group as the frequency of each cleft type was small, and the literature has shown that CLP type has little influence on severity of psychosocial impairment. ${ }^{6,20}$ The median OHIP-14 score in the CLP group was six-fold higher than in the CONT demonstrating significant residual OHRQoL impact after the completion of care. Foo et al. ${ }^{5}$ also found that OHIP-14 scores in adult CLP subjects were 1.7fold higher than the "South Australian 2002 statelevel norms".

Although an additive OHIP score is the most frequent method used to assess overall quality of life, the analysis by item prevalence (\%FOVO) allows identification of items (and thereby of domains) with a greater magnitude of impact on OHRQoL, at a level more likely to require treatment. ${ }^{18} \mathrm{FOVO}$ analysis for the CLP group showed that psychological discomfort and psychological disability made the greatest contribution to the score with embarrassment, being self-conscious or tense and pronunciation as the top 4 ranked questions in terms of impact difference compared with controls. The CLP group also reported more psychological distress than either DENT or CONT, but were not clinically depressed. It is unclear whether these outcomes relate to oral function in terms of the dentition or residual speech and aesthetic concerns subsequent to complex rehabilitative care 
and speech therapy. ${ }^{21}$ Dissatisfaction with facial appearance seems to be a predictor of depressive symptoms in CLP subjects, $, 6,6,22,23$ and symptoms of depression and anxiety may be twice as prevalent among CLP adults compared with CONT. ${ }^{24,25}$ It is likely that a generic OHRQoL instrument such as OHIP-14 will not identify and measure the specific problems such as social adjustment, self-esteem, facial appearance, symptoms of depression, and speech in this population. ${ }^{1,2}$ Currently, there is no specific instrument designed to capture the life-long and complex implications of clefts. ${ }^{26} \mathrm{~A}$ thorough assessment of the impact of clefts on psychosocial distress and well-being using a mixed-methods (qualitative and quantitative) approach may help produce a more sensitive instrument for assessing condition-specific problems unique to CLP patients.

In terms of function, the CLP group had reduced MBF compared with CONT and reported some significant limitations in terms of foods choice / texture preference. This is the first time data of this sort is presented, and it is unclear why this population have these limitations after the completion of rehabilitation. Maybe the stability of the cleft repair is not as great as a "normal" maxilla and hence a reduction in bite force. Furthermore, there may be some residual relative movement of the palatal fragments increasing the risk of food packing. The nature of the restorative care for these subjects was also heterogeneous as it was determined by their clinical needs. The sample was also too small to identify whether specific forms of rehabilitation were associated with altered food choice. The pattern of texture preference and food avoidance was, however, remarkably similar to the DENT group.

This is the first report in the literature describing function and OHRQoL for people who are edentulous in the maxilla but have a natural or prosthetically restored mandibular dentition. Subjects who have teeth in the mandible would normally be recorded as partially dentate, however a significant proportion of adults in this category have a complete maxillary denture $(18.2 \%$ of the adult population of Brazil, for example). ${ }^{27,28}$ Most previous data relating to OHRQoL for people using complete dentures has been for those who are edentulous in both jaws. Interestingly,
$13 \%$ of the UK adult population with a combination of dentures and natural teeth reported the most problems with dental conditions. ${ }^{29}$

The pattern of OHIP-14 responses in DENT was heterogeneous with a markedly skewed distribution and some extreme values of subjects dissatisfied with their OHRQoL. This made analysis of these data using means and standard deviations inappropriate. Analysis of the medians / interquartile ranges showed similarly high satisfaction and perceived well-being despite reported alterations with food choice and dietary limitations. The OHIP-14 prevalence analysis in DENT showed scattered distribution of items in multiple domains, such as functional limitation, physical disability, physical pain, psychosocial disability, and psychological discomfort. This differed from the predominance of psychological complaints in the CLP group when the median severity OHIPADD scores were analyzed.

One possible explanation is that the subjects in this sample had worn the same maxillary complete dentures for at least six months, i.e., they were adapted to some extent. Previous studies showed that a stable and retentive maxillary denture with adequate articulation has a positive effect on the satisfaction and well-being of denture wearers, ${ }^{10}$ and prosthesis quality is associated with OHRQoL.,30 Therefore, the oral rehabilitation with conventional complete dentures may represent a return to a normal or quasi-normal lifestyle for some edentate patients who do not have great expectations. ${ }^{10,12}$ There was a small number of these subjects who reported a very significant level of impact on their OHRQoL.

The DENT group also had lower maximum bite force than controls, with no difference between DENT and CLP; they also avoided hard and raw food textures. The main difference between both groups were the types of food avoided or difficult to chew. Most CLP subjects avoid eating corn on the cob possibly due to the congenital instability of the pre-maxilla. The DENT group reported more difficulties with gum and caramel candies, as well as sticky textures that might dislodge the denture during chewing. A number of different foods difficult to chew were also avoided by both CLP and DENT, 
such as nuts, carrot, and apple skin. Crunchy and raw textures were also avoided. Subjective perception of many factors, such as taste, smell, texture, and color, have been related to food avoidance and chewing strategies. ${ }^{14,31,32}$ Further studies with people who are edentulous in the maxilla are warranted to better describe this population and understand their functional problems.

Some limitations of the present study are the small sample size and the impracticality of obtaining agematched groups. However, the literature has shown that the direct effects of age on functional tooth units and bite force are relatively small, ${ }^{16,32}$ and that age in CLP subjects does not influence psychosocial problems. ${ }^{6}$ The non-significance of some variables, such as bruxism and pain is probably related to the low frequency of these conditions in the sample, which was not selected among patients from dental clinics specialized in orofacial pain and temporomandibular disorders. Nevertheless, the actual sample size allowed significant and relevant findings within the present statistical approach.

\section{References}

1. Preshaw PM, Walls AW, Jakubovics NS, Moynihan PJ, Jepson NJ, Loewy Z. Association of removable partial denture use with oral and systemic health. J Dent. 2011 Nov;39(11):711-9. https://doi.org/10.1016/i.jdent.2011.08.018

2. Tan $H$, Peres KG, Peres MA. Retention of teeth and oral healthrelated quality of life. J Dent Res. 2016 Nov;95(12):1350-7. https://doi.org/10.1177/0022034516657992

3. Glick M, Williams DM, Kleinman DV, Vujicic M, Watt RG, Weyant RJ. A new definition for oral health supported by FDI opens the door to a universal definition of oral health. J Dent. 2017 Feb;57:1-3. https://doi.org/10.1016/i.jdent.2016.12.005

4. Kassebaum NJ, Smith AG, Bernabé E, Fleming TD, Reynolds $A E$, Vos T et al. Global, regional, and national prevalence, incidence, and disability-adjusted life years for oral conditions for 195 countries, 1990-2015: a systematic analysis for the global burden of diseases, injuries, and risk factors. J Dent Res. 2017 Apr;96(4):380-7. https://doi.org/10.1177/0022034517693566

5. Foo P, Sampson W, Roberts R, Jamieson L, David D. General health-related quality of life and oral health impact among Australians with cleft compared with population norms; age and gender differences. Cleft Palate Craniofac J. 2012 Jul;49(4):406-13. https://doi.org/10.1597/10-126

\section{Conclusion}

In summary, the results suggest that this sample of treated adult subjects with CLP or DENT still have perceived chewing problems and lower bite force than control healthy subjects. OHRQoL is mostly influenced by psychological aspects for CLP subjects and by functional items for DENT subjects. CLP showed statistically more depression symptoms than DENT and controls subjects, but the score was within normal range and not clinically relevant. Although oral rehabilitation is necessary for technical restoration of function and esthetics, it may not be sufficient to improve patient-centered outcomes to optimal levels, which require an individualized qualitative approach to solve specific complaints.

\section{Acknowledgements}

This research was supported by the CAPES. The authors declare that they have no conflict of interest. The authors thank all patients who participated in this study and PUCRS staff.
6. Hunt $\mathrm{O}$, Burden D, Hepper $\mathrm{P}$, Johnston $\mathrm{C}$. The psychosocial effects of cleft lip and palate: a systematic review. Eur J Orthod. 2005 Jun;27(3):274-85. https://doi.org/10.1093/ejo/cji004

7. Semb G, Brattström V, Mølsted K, Prahl-Andersen B, Zuurbier P, Rumsey $\mathrm{N}$ et al. The Eurocleft study: intercenter study of treatment outcome in patients with complete cleft lip and palate. Part 4: Relationship among treatment outcome, patient/parent Satisfaction, and the burden of care. Cleft Palate Craniofac J. 2005;42(1):64-8. https://doi.org/10.1597/02-119.1.1

8. Oosterkamp BC, Dijkstra PU, Remmelink HJ, Oort RP, Goorhuis-Brouwer SM, Sandham A et al. Satisfaction with treatment outcome in bilateral cleft lip and palate patients. Int J Oral Maxillofac Surg. 2007 Oct;36(10):890-5. https://doi.org/10.1016/i.ijom.2007.07.008

9. Mossey PA, Little J, Munger RG, Dixon MJ, Shaw WC. Cleft lip and palate. Lancet. 2009 Nov;374(9703):1773-85. https://doi.org/10.1016/S0140-6736(09)60695-4

10. Chen YF, Yang YH, Chen JH, Lee HE, Lin YC, Ebinger J et al. The impact of complete dentures on the oral helath-related quality of life among elderly. J Dent Sci. 2012 Sep;7(3):289-95. https://doi.org/10.1016/j.jds.2012.06.004 
11. Montero J, Castillo-Oyagüe R, Lynch CD, Albaladejo A, Castaño A. Self-perceived changes in oral health-related quality of life after receiving different types of conventional prosthetic treatments: a cohort follow-up study. J Dent. 2013 Jun;41(6):493503. https://doi.org/10.1016/i.jdent.2013.01.006

12. Nordenram G, Davidson T, Gynther G, Helgesson G, Hultin M, Jemt T et al. Qualitative studies of patients' perceptions of loss of teeth, the edentulous state and prosthetic rehabilitation: a systematic review with metasynthesis. Acta Odontol Scand. 2013 May-Jul;71(3-4):937-51. https://doi.org/10.3109/00016357.2012.734421

13. Slade GD. Derivation and validation of a shortform oral health impact profile. Community Dent Oral Epidemiol. 1997 Aug;25(4):284-90. https://doi.org/10.1111/j.1600-0528.1997.tb00941.x

14. Obrez A, Grussing PG. Opinions and feelings on eating with complete dentures: a qualitative inquiry. Spec Care Dentist. 1999 Sep-Oct;19(5):225-9. https://doi.org/10.1111/j.1754-4505.1999.tb01390.x

15. Dworkin SF, LeResche L. Research diagnostic criteria for temporomandibular disorders: review, criteria, examinations and specifications, critique. J Craniomandib Disord. 1992;6(4):301-55. PMID:1298767

16. Hatch JP, Shinkai RS, Sakai S, Rugh JD, Paunovich ED. Determinants of masticatory performance in dentate adults. Arch Oral Biol. 2001 Jul;46(7):641-8. https://doi.org/10.1016/S0003-9969(01)00023-1

17. Slade GD, Strauss RP, Atchison KA, Kressin NR, Locker D, Reisine ST. Conference summary: assessing oral health outcomes-measuring health status and quality of life. Community Dent Health. 1998 Mar;15(1):3-7.

18. Moufti MA, Wassell RW, Meechan JG, Allen PF, John MT, Steele JG. The Oral Health Impact Profile: ranking of items for temporomandibular disorders. Eur J Oral Sci. 2011 Apr;119(2):16974. https://doi.org/10.1111/j.1600-0722.2011.00809.x

19. Dworkin SF, Huggins KH, Wilson L, Mancl L, Turner JA, Massoth D et al. LeResche Linda, Truelove E. A randomized clinical trial of a tailored comprehensive care treatment program for temporomandibular disorders. J Orofac Pain. 2002;16(4):259-76

20. Sinko K, Jagsch R, Prechtl V, Watzinger F, Hollmann $\mathrm{K}$, Baumann A. Evaluation of esthetic, functional, and quality-of-life outcome in adult cleft lip and palate patients. Cleft Palate Craniofac J. 2005 Jul;42(4):355-61. https://doi.org/10.1597/03-142.1

21. Hickey AJ, Salter M. Prosthodontic and psychological factors in treating patients with congenital and craniofacial defects. J Prosthet Dent. 2006 May;95(5):392-6. https://doi.org/10.1016/i.prosdent.2006.03.002

22. Marcusson A, List T, Paulin G, Dworkin S. Temporomandibular disorders in adults with repaired cleft lip and palate: a comparison with controls. Eur J Orthod. 2001 Apr;23(2):193204. https://doi.org/10.1093/ejo/23.2.193
23. Oliveira RL, Santos TS, Teixeira JLA, Martins-Filho PR, Silva LC. Health-related quality of life patients with a cleft lip and/or palate. J Craniofac Surg. 2015 Nov;26(8):2315-9. https://doi.org/10.1097/SCS.0000000000001992

24. Ramstad T, Ottem E, Shaw WC. Psychosocial adjustment in Norwegian adults who had undergone standardised treatment of complete cleft lip and palate. II. Self-reported problems and concerns with appearance. Scand J Plast Reconstr Surg Hand Surg. 1995 Dec;29(4):329-36. https://doi.org/10.3109/02844319509008968

25. Mani M, Carlsson M, Marcusson A. Quality of life varies with gender and age among adults treated for unilateral cleft lip and palate. Cleft Palate Craniofac J. 2010 Sep;47(5):491-8. https://doi.org/10.1597/08-281

26. Eckstein DA, Wu RL, Akinbiyi T, Silver L, Taub PJ. Measuring quality of life in cleft lip and palate patients: currently available patient-reported outcomes measures. Plast Reconstr Surg. 2011;128(5):518e-26. https://doi.org/10.1097/PRS.0b013e31822b6a67

27. Ribeiro MT, Rosa MA, Lima RM, Vargas AM, Haddad $J P$, Ferreira E. Edentulism and shortened dental arch in Brazilian elderly from the National Survey of Oral Health 2003. Rev Saude Publica. 2011 Oct;45(5):817-23. https://doi.org/10.1590/S0034-89102011005000057

28. Ministério da Saúde (BR). Secretaria de Atenção à Saúde. Coordenação Nacional de Saúde Bucal. Projeto SB Brasil 2010: resultados principais. Brasília, DF: Ministério da Saúde; 2011.

29. Nuttall N, Tsakos G, Lader D, Hill K. Outcome and impact: a report from the Adult Dental Health Survey 2009. London: The Health and Social Care Information Centre; 2011. [cited 2013 Oct 20], Available from: http://content.digital.nhs.uk/catalogue/ PUB01086/adul-dent-heal-surv-summ-them-the7-2009-rep9.pdf

30. John MT, Slade GD, Szentpétery A, Setz JM. Oral healthrelated quality of life in patients treated with fixed, removable, and complete dentures 1 month and 6 to 12 months after treatment. Int J Prosthodont. 2004 Sep-Oct;17(5):503-11.

31. Walls AW, Steele JG, Sheiham A, Marcenes W, Moynihan PJ. Oral health and nutrition in older people. J Public Health Dent. 2000;60(4):304-7. https://doi.org/10.1111/j.1752-7325.2000.tb03339.x

32. Iwasaki M, Taylor GW, Manz MC, Yoshihara A, Sato M, Muramatsu $\mathrm{K}$ et al. Oral health status: relationship to nutrient and food intake among 80-year-old Japanese adults. Community Dent Oral Epidemiol. 2014 Oct;42(5):441-50. https://doi.org/10.1111/cdoe.12100

33. Lobbezoo F, Ahlberg J, Glaros AG, Kato T, Koyano $K$, Lavigne GJ et al. Bruxism defined and graded: an international consensus. J Oral Rehabil. 2013 Jan;40(1):2-4. https://doi.org/10.1111/joor.12011

34. International RDC/TMD Consortium Network. Buffalo: International RDC/TMD Consortium Network; 2013 [cited 2013 Nov 27]. Available from: https://ubwp.buffalo.edu/rdctmdinternational 